\title{
National survey of Korean hepatobiliary-pancreatic surgeons on attitudes about the enhanced recovery after surgery protocol
}

\author{
Sang Hyun Shin ${ }^{1, *}$, Woo-hyoung Kang ${ }^{2, *}$, In Woong Han ${ }^{1}$, Yunghun You ${ }^{1}$, Huisong Lee ${ }^{3}$, \\ Hongbeom Kim ${ }^{4}$, Woohyun Jung ${ }^{5}$, Yong Chan Shin ${ }^{6}$, and Jin Seok $\mathrm{Heo}^{1}$
}

${ }^{1}$ Division of Hepatobiliary-Pancreatic Surgery, Department of Surgery, Samsung Medical Center, Sungkyunkwan University School of Medicine, '2Division of Liver Transplantation and Hepatobiliary Surgery, Department of Surgery, Asan Medical Center, University of Ulsan College of Medicine,

${ }^{3}$ Department of Surgery, Ewha Womans University College of Medicine, ${ }^{4}$ Department of Surgery, Seoul National University Hospital, Seoul, ${ }^{5}$ Department of Surgery, Ajou University School of Medicine, Suwon, ${ }^{6}$ Department of Surgery, Inje University College of Medicine, Inje University Ilsan Paik Hospital, Goyang, Korea

Backgrounds/Aims: The purpose of this study was to investigate attitudes regarding the Enhanced Recovery After Surgery (ERAS) protocol of hepato-biliary-pancreatic (HBP) surgeons in Korea and the extent to which they use the protocol for perioperative management. Methods: An online survey was conducted among members of the Korean Association of Hepato-Biliary-Pancreatic Surgery (KAHBPS) for eight weeks beginning on August 2019. The questionnaire, which was written in Korean, was based on the latest ERAS guidelines. Total responses were collected from 127 surgeons. Results: Of the 127 total respondents, the largest proportion (44.9\%) were working in Seoul. In terms of established in-hospital clinical pathways (CP), $19.7 \%$ of the participating surgeons had and followed a CP in pancreaticoduodenectomy (PD) and $21.3 \%$ in hepatectomy. Regarding the ERAS protocol for each surgery, four items $(18.2 \%)$ regarding $\mathrm{PD}$ and seven items $(35.0 \%)$ related to hepatectomy were followed by more than $50 \%$ of respondents. Conclusions: ERAS guidelines are one of the consensuses for better recovery in perioperative management of patients undergoing major surgeries and encompass the overall process of patient recovery including patient education, pain control, physiologic balance, and perioperative nutrition. A novel project is needed to successfully implement an evidence-based enhanced recovery strategy. (Ann Hepatobiliary Pancreat Surg 2020;24:477-483)

Key Words: ERAS; HBP; Pancreaticoduodenectomy; Hepatectomy

\section{INTRODUCTION}

In the 2000s, there have been many advances in surgical techniques and pre- and post-operative management in various abdominal surgeries. Based on these advances, a group of European academic surgeons ${ }^{1,2}$ developed an enhanced recovery pathway, and the Enhanced Recovery After Surgery (ERAS) study group was launched in London in 2001. ERAS is a multimodal pathway developed to improve recovery after major surgery, and a guideline for colorectal resection was proposed in 2005 . Since then, the protocol has been extended to other spe- cialties including urologic, thoracic, vascular and orthopedic surgery. More recently, it has included pancreatoduodenectomy (PD) in $2012^{3}$ and liver surgery in $2016 .^{4}$

The purpose of the ERAS guidelines is to provide evidence-based, standardized processes for minimizing surgical stress and restoring normal physiological conditions after surgery. The goal is to provide faster functional recovery and significant reduction in postoperative complications, early return to daily life, short hospital stay, and cost effectiveness. It not only refers to the "fast track" of recovery, but also includes the overall multidisciplinary approach to patient recovery including patient education,

Received: June 22, 2020; Revised: July 10, 2020; Accepted: July 12, 2020

Corresponding author: Jin Seok Heo

Division of Hepatobiliary-Pancreatic Surgery, Department of Surgery, Samsung Medical Center, Sungkyunkwan University School of Medicine, 81 Irwon-ro, Gangnam-gu, Seoul 06351, Korea

Tel: +82-2-3410-1089, Fax: +82-2-3410-6980, E-mail: jsheo.md@gmail.com

*Sang Hyun Shin and Woo-hyoung Kang contributed equally to this study and should be considered as co-first authors.

Copyright (C) 2020 by The Korean Association of Hepato-Biliary-Pancreatic Surgery

This is an Open Access article distributed under the terms of the Creative Commons Attribution Non-Commercial License (http://creativecommons.org/ licenses/by-nc/4.0) which permits unrestricted non-commercial use, distribution, and reproduction in any medium, provided the original work is properly cited. Annals of Hepato-Biliary-Pancreatic Surgery • pISSN: 2508-5778 • elSSN: 2508-5859 
pain control, physiologic balance, and nutrition.

Based on evidence, ERAS guidelines have been implemented in many countries and centers, demonstrating their benefits, and they have been revised as necessary according to a specific audit system. ${ }^{5,6}$ Until recently, implementation and verification of ERAS guidelines were primarily conducted for colorectal surgery; related research is being carried out in complex and difficult hepato-biliary-pancreas (HBP) surgeries. ${ }^{7-10}$ Postoperative recovery from HBP surgery has historically been known to have a high incidence of complications including perioperative hemorrhage, infection, poor pain control, and prolonged intensive care and hospital stays. However, with recent developments in surgical techniques and patient monitoring and management, postoperative complications are decreasing, and it is reasonable to implement ERAS guidelines.

The purpose of this study was to investigate the recognition and extent of application of ERAS guidelines by Korean surgeons who actively perform hepatobiliary and pancreatic surgery.

\section{MATERIALS AND METHODS}

\section{Survey and data collection}

This study was approved by Institutional Review Board of Samsung Medical Center (approval number: 2020-03133). An online survey was conducted among members of the Korean Association of Hepato-Biliary-Pancreatic Surgery (KAHBPS) for eight weeks from August 2019. The questionnaire, which was written in Korean, was based on the latest ERAS guidelines. ${ }^{4,11}$ It had six common questions of respondent age, size of hospital, number of operations, existence of in-hospital clinical pathways (CP), and an individual question related to each PD and hepatectomy. Each question addressed compliance and surgeon preference regarding the ERAS guidelines. Each personal device (computer or mobile) could be used only once for the survey, and duplicate replies were not valid. Total responses were collected from 127 surgeons, which included replies from 113 surgeons performing PD and 107 surgeons performing hepatectomy.

\section{RESULTS}

Among the 127 total respondents, 57 (44.9\%) were working in Seoul, followed by Gyeongsang-do (18.1\%), Gyeonggi-do (17.3\%), Chungcheong-do (11.0\%), Jeolla-do (6.3\%), and Gangwon-do (2.4\%). Most of the surgeons were working in medium- to large-sized hospitals with more than 500 beds $(93.7 \%)$ (Table 1). Among the respondents, $66.1 \%$ were from a hospital performing more than two PDs per month ( $\geq 26$ cases per year), and $78 \%$ were from a hospital performing more than two hepatectomies per month ( $\geq 26$ cases per year). In terms of established in-hospital CP, surgeons who had and followed a

Table 1. Reponses to common questions of the survey from members of Korean Association of Hepato-Biliary-Pancreatic Surgery $(n=127)$

\begin{tabular}{lr}
\hline \multicolumn{1}{c}{ Common question } & No. (\%) \\
\hline Regional distribution of respondents & \\
Seoul & $57(44.9)$ \\
Gyeonggi-do & $22(17.3)$ \\
Chungcheong-do & $14(11.0)$ \\
Jeolla-do & $8(6.3)$ \\
Gyeongsang-do & $23(18.1)$ \\
Gangwon-do & $3(2.4)$ \\
Size of a center of respondent & \\
$<500$ beds & $8(6.3)$ \\
$501-1000$ beds & $70(55.1)$ \\
$>1000$ beds & $49(38.6)$ \\
No. of pancreaticoduodenectomy performed per & \\
year by a center & \\
$<25$ cases & $43(33.9)$ \\
$26-50$ cases & $43(33.9)$ \\
$51-100$ cases & $15(11.8)$ \\
$>100$ cases & $26(20.4)$ \\
No. of liver surgery performed per year by & \\
a center & \\
$<25$ cases & $28(22.0)$ \\
$26-50$ cases & $31(24.4)$ \\
$51-100$ cases & $31(24.4)$ \\
$>100$ cases & $37(29.2)$ \\
In-hospital clinical pathway of & \\
pancreaticoduodenectomy & \\
Having, and following clinical pathway & $25(19.7)$ \\
Having, but not following clinical pathway & $43(33.8)$ \\
Not having clinical pathway & $58(45.7)$ \\
Unknown & $10.8)$ \\
In-hospital clinical pathway of hepatectomy & \\
Having, and following clinical pathway & $27(21.3)$ \\
Having, but not following clinical pathway & $45(35.4)$ \\
Not having clinical pathway & $54(42.5)$ \\
Unknown & $10.8)$ \\
\hline
\end{tabular}


CP represented $19.7 \%$ in $\mathrm{PD}$ and $21.3 \%$ in hepatectomy. Most respondents did not have a $\mathrm{CP}$ protocol, and if they did, they performed postoperative management based on personal preferences rather than a $\mathrm{CP}$.

In the responses about individual surgery, 113 of 127 respondents were performing $\mathrm{PD}, 107$ hepatectomy, and
97 both surgeries. Table 2 shows the respondent responses to implementation and preference for the ERAS protocol for each surgery. More than $50 \%$ of the respondents reported that they would perform postoperative management according to the ERAS protocol in only four items of PD and seven items of hepatectomy, Considering that four

Table 2. Numbers and percentages of Korean hepato-biliary-pancreatic surgeons following recommendations of enhanced recovery after surgery (ERAS) items in pancreaticoduodenectomy and hepatectomy

\begin{tabular}{|c|c|}
\hline Item & No. $(\%)$ \\
\hline \multicolumn{2}{|l|}{ Pancreaticoduodenectomy $(n=113)$} \\
\hline Preoperative counselling & $19(16.8)$ \\
\hline Perioperative biliary drainage & $15(13.3)$ \\
\hline Preoperative smoking and alcohol consumption & $25(22.1)$ \\
\hline Preoperative nutrition & $41(36.3)$ \\
\hline Perioperative oral immunonutrition & $6(5.3)$ \\
\hline Oral bowel preparation & $50(44.2)$ \\
\hline Preoperative fasting & $13(11.5)$ \\
\hline Preanaestheticmedication & $51(45.1)$ \\
\hline Anti-thrombotic prophylaxis & $3(2.7)$ \\
\hline Antimicrobial prophylaxis and skin preparation & $106(93.8)$ \\
\hline Epidural analgesia & $13(11.5)$ \\
\hline Wound catheters and transversus abdominis plane block & $17(15.0)$ \\
\hline Preventing postoperative nausea and vomiting & $25(22.1)$ \\
\hline Avoiding hypothermia & $87(77.0)$ \\
\hline Postoperative glycemic control & $24(21.2)$ \\
\hline Nasogastric intubation & $20(17.7)$ \\
\hline Fluid balance & $8(7.1)$ \\
\hline Perianastomotic drain & $15(13.3)$ \\
\hline Somatostatin analogues & $36(31.9)$ \\
\hline Urinary drainage & $96(85.0)$ \\
\hline Stimulation of bowel movement & $4(3.5)$ \\
\hline Early and scheduled mobilization & $60(53.1)$ \\
\hline \multicolumn{2}{|l|}{ Hepatectomy $(n=107)$} \\
\hline Preoperative counselling & $17(15.9)$ \\
\hline Preoperative nutrition & $13(12.1)$ \\
\hline Perioperative oral immunonutrition & No specific recommendation \\
\hline Preoperative fasting & $6(5.6)$ \\
\hline Oral bowel preparation & $71(66.4)$ \\
\hline Preanesthetic medication & $44(41.1)$ \\
\hline Anti-thrombotic prophylaxis & $10(9.3)$ \\
\hline Perioperative steroids administration & No specific recommendation \\
\hline Antimicrobial prophylaxis and skin preparation & $22(20.6)$ \\
\hline Minimally invasive approach & $27(25.2)$ \\
\hline Nasogastric intubation & $46(43.0)$ \\
\hline Prophylactic abdominal drainage & No specific recommendation \\
\hline Preventing intraoperative hypothermia & $81(75.7)$ \\
\hline Postoperative nutrition and early oral intake & $29(27.1)$ \\
\hline Preventing delayed gastric emptying & $9(8.4)$ \\
\hline Stimulation of bowel movement & No specific recommendation \\
\hline Early mobilization & $52(48.6)$ \\
\hline Analgesia & $8(7.5)$ \\
\hline Preventing postoperative nausea and vomiting & $37(34.6)$ \\
\hline Fluid management & $87(81.3)$ \\
\hline
\end{tabular}


items in hepatectomy, perioperative oral immunonutrition, perioperative steroids administration, prophylactic abdominal drainage, and stimulation of bowel movement, do not have specific recommendations, three items were accepted by more than $50 \%$ of respondents.

Details of personal preferences for several ERAS items are shown in Figures. Regarding PD, the ERAS protocol does not recommend routine biliary drainage in patients with serum bilirubin concentration $<250 \mu \mathrm{mol} / \mathrm{L}$, but most respondents $(87 \%)$ were performing prophylactic biliary drainage before surgery (Fig. 1A). Although ERAS protocol recommends intake of clear fluids up to two hours and intake of solids up to six hours before anesthesia, most surgeons still tend to prefer preoperative fast-

\section{A}

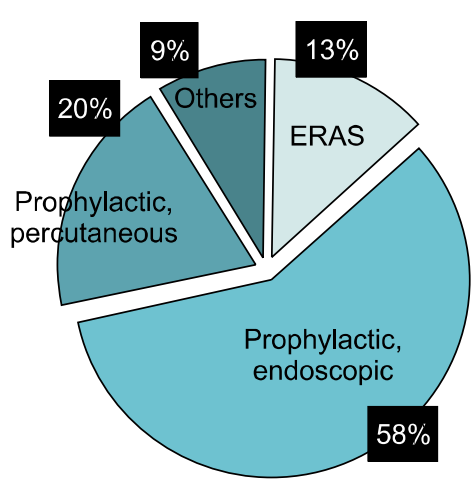

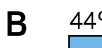

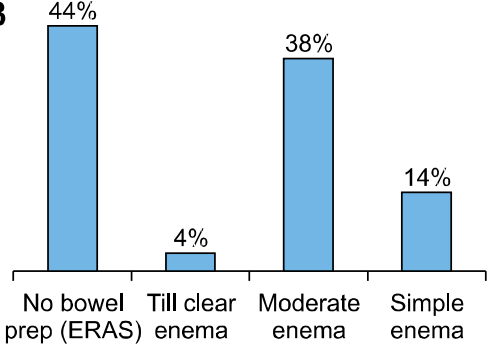

D

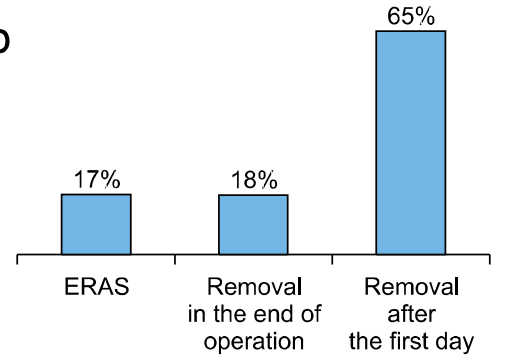

C

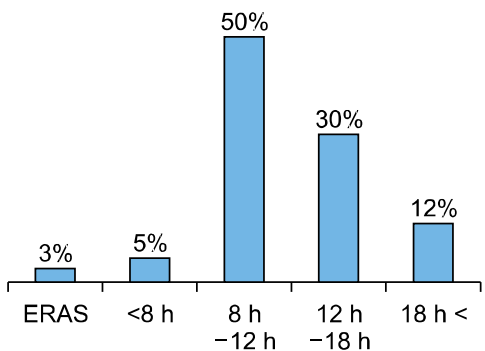

E

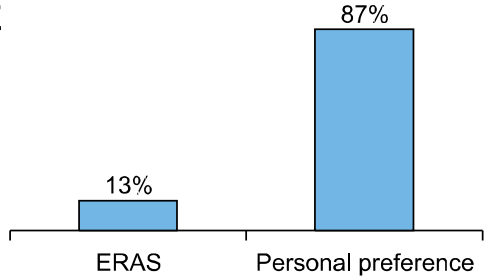

Fig. 1. Personal preferences following enhanced recovery after surgery (ERAS) guideline of pancreaticoduodenectomy. (A) Preoperative biliary drainage, (B) preoperative oral bowel preparation, (C) preoperative fasting, (D) nasogastric intubation, and (E) perianastomotic drain.

A

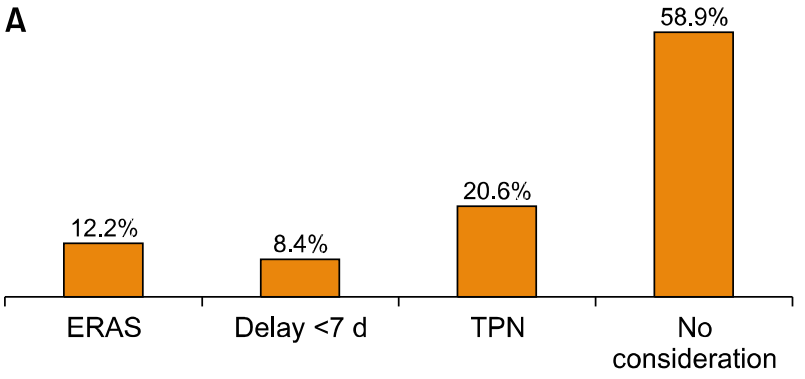

C

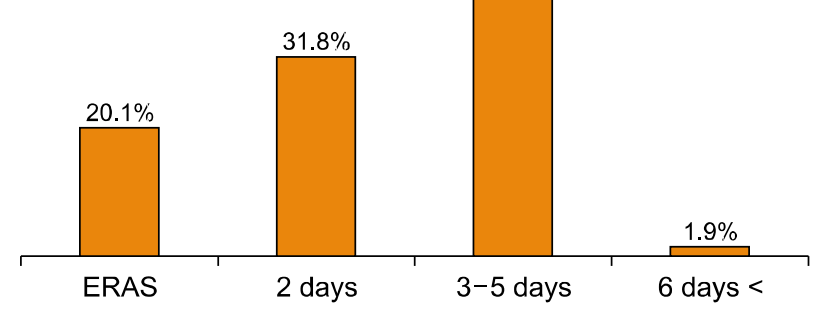

B

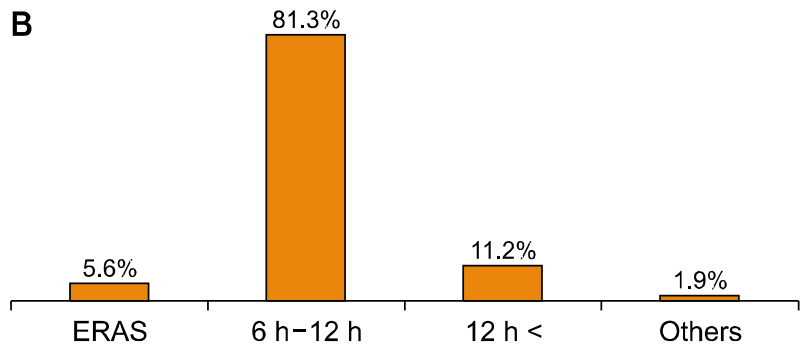

D

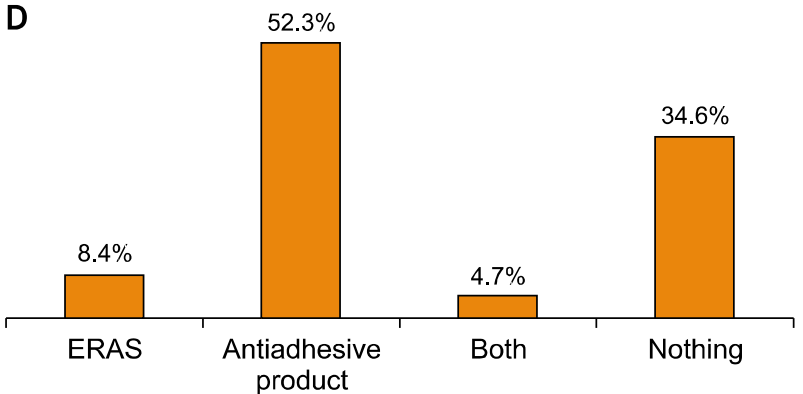

Fig. 2. Personal preferences following enhanced recovery after surgery (ERAS) guideline of liver surgery. (A) Preoperative nutrition, (B) preoperative fasting, (C) antimicrobial prophylaxis, and (D) prevention of delayed gastric emptying. 
ing for more than eight hours (Fig. 1C). In terms of perianastomotic drains, personal preferences of surgeons were the most important determinant regardless of specific criteria (Fig. 1E). In hepatectomy, there were more surgeons who did not consider preoperative nutrition (Fig. 2A), and the responses for preoperative fasting were like those of PD (Fig. 2B). To prevent delayed gastric emptying after left-sided hepatectomy, more surgeons preferred to use a commercial anti-adhesive agent rather than covering omental flap recommended by ERAS protocol (Fig. 2D).

\section{DISCUSSION}

Although surgeries of the HBP area are complicated and life-threatening, advances in surgical techniques and perioperative management have led to performance of these surgeries with acceptable morbidity and mortality. ${ }^{12-17}$ Considering these advances, this survey was conducted to determine the contribution of ERAS guidelines, a major change in perioperative management, to actual clinical practice in Korea, and to determine future improvements. Survey results demonstrated that the ERAS guidelines were less actively accepted in Korean HBP surgeons than expected, and that traditional practice based on experience was still trusted more than evidence-based guidelines.

The researchers identified four reasons that are likely to hinder implementation of the ERAS guidelines in Korean HBP clinical practice. First, there is a misunderstanding of the guidelines' purpose. Previous studies on ERAS protocols have emphasized that implementation of these new protocols can yield earlier recovery and subsequent decrease in length of hospital stay. ${ }^{7,9,18-22}$ These repetitive results have been misleading as if the ERAS protocol was dedicated to rapid recovery. However, an ERAS protocol is an evidence-based guideline containing the overall process of patient recovery including patient education, pain control, physiologic balance, and perioperative nutrition. The protocol has been reported to be associated with enhanced recovery of patients and a lower probability of morbidity; however, it is necessary to understand that early return to normal life is not the primary purpose but the beneficial result of enhanced recovery.

The second reason why ERAS protocol is not properly implemented is that some of their items are complicated and obscure. The PD and hepatectomy guidelines used in this survey included 28 and 23 items, respectively. Some of these items are easily accessible, but others require close cooperation with various departments, such as anesthesiology, and yet others are confusing because they fail to provide specific recommendations. For example, items such as perioperative oral immunonutrition or anti-thrombotic prophylaxis in PD have significant limitations for application in actual clinical situations, and there are items that confuse readers rather than providing clear recommendations, with ambiguous expressions such as "steroids may be used" in hepatectomy. This complexity and ambiguity pose one of the biggest obstacles to implementing these new protocols in HBP surgery with a wide variety of perioperative courses.

The third and fourth reasons why ERAS protocols are not properly implemented are that the recommendations have large discrepancies with traditional management and the fear caused by big changes. ERAS guidelines for PD and hepatectomy recommend that preoperative mechanical bowel preparation has no proven benefit, preoperative fasting does not need to exceed six hours for solids and two hours for liquids, and early removal of perianastomotic drains after 72 hours in PD may be advisable in patients at low risk (i.e., amylase content in drain $<5000 \mathrm{U} / \mathrm{L}$ ) for developing a pancreatic fistula. These recommendations have already been proven repeatedly in previous studies, ${ }^{23-26}$ and most surgeons know the advantages of performing them. However, through the survey administered in the current study, the researchers identified that a large percentage of surgeons maintain traditional methods, and it is very difficult to change traditional experience-based practice to novel, evidence-based management, even if the evidence is obvious.

Although this survey has a limitation that 127 respondents do not represent all Korean HBP surgeons, participant responses may be credible given that there are approximately 260 active participants in the Korean HBP society.

ERAS protocols may not be an absolute guide for patient management. However, they are one of the consensuses for better recovery in perioperative management of patients undergoing these major surgeries. The protocols encompass the overall process of patient recovery including patient education, pain control, physiologic bal- 
ance, and perioperative nutrition. The high-level evidences have already been demonstrated and are also in progress. Therefore, a novel project is needed to successfully implement an evidence-based enhanced recovery strategy that encompasses preoperative counseling, perioperative modulation of physiologic balance, and postoperative early restoration of normal nutritional status.

\section{ACKNOWLEDGEMENTS}

The authors would like to thank all members of the KAHBPS who took the time to fill out the survey.

\section{CONFLICT OF INTEREST}

All the authors declare that they have no conflict of interest.

\section{ORCID}

Sang Hyun Shin: https://orcid.org/0000-0002-2533-4491

Woo-hyoung Kang: https://orcid.org/0000-0002-3734-3352

In Woong Han: https://orcid.org/0000-0001-7093-2469

Yunghun You: https://orcid.org/0000-0002-0684-7523

Huisong Lee: https://orcid.org/0000-0002-3565-6064

Hongbeom Kim: https://orcid.org/0000-0002-1595-0135

Woohyun Jung: https://orcid.org/0000-0003-1484-9024

Yong Chan Shin: https://orcid.org/0000-0001-9808-1213

Jin Seok Heo: https://orcid.org/0000-0001-6767-2790

\section{AUTHOR CONTRIBUTIONS}

Conceptualization: SHS, WK, IWH, YY, HL, HK, WJ, YCS, JSH. Data curation: SHS, WK, IWH, JSH. Methodology: SHS, WK, IWH, YY, HL, HK, WJ, YCS, JSH. Project administration: SHS, WK, IWH, JSH. Visualization: SHS, WK. Writing - original draft: SHS, WK. Writing - review \& editing: SHS, WK, IWH, YY, HL, HK, WJ, YCS, JSH.

\section{REFERENCES}

1. Bardram L, Funch-Jensen P, Jensen P, Crawford ME, Kehlet H. Recovery after laparoscopic colonic surgery with epidural analgesia, and early oral nutrition and mobilisation. Lancet 1995;
345:763-764.

2. Kehlet H, Mogensen T. Hospital stay of 2 days after open sigmoidectomy with a multimodal rehabilitation programme. $\mathrm{Br} \mathrm{J}$ Surg 1999;86:227-230.

3. Lassen K, Coolsen MM, Slim K, Carli F, de Aguilar-Nascimento JE, Schäfer M, et al. Guidelines for perioperative care for pancreaticoduodenectomy: Enhanced Recovery After Surgery $\left(\right.$ ERAS $^{\mathbb{R}}$ ) Society recommendations. Clin Nutr 2012;31:817-830.

4. Melloul E, Hübner M, Scott M, Snowden C, Prentis J, Dejong $\mathrm{CH}$, et al. Guidelines for perioperative care for liver surgery: Enhanced Recovery After Surgery (ERAS) Society recommendations. World J Surg 2016;40:2425-2440.

5. Ljungqvist O, Scott M, Fearon KC. Enhanced recovery after surgery: a review. JAMA Surg 2017;152:292-298.

6. Gustafsson UO, Hausel J, Thorell A, Ljungqvist O, Soop M, Nygren J. Adherence to the enhanced recovery after surgery protocol and outcomes after colorectal cancer surgery. Arch Surg 2011;146:571-577.

7. Savikko J, Ilmakunnas M, Mäkisalo H, Nordin A, Isoniemi H. Enhanced recovery protocol after liver resection. Br J Surg 2015; 102:1526-1532.

8. Rouxel P, Beloeil H. Enhanced recovery after hepatectomy: a systematic review. Anaesth Crit Care Pain Med 2019;38:29-34.

9. Hwang DW, Kim HJ, Lee JH, Song KB, Kim MH, Lee SK, et al. Effect of Enhanced Recovery After Surgery program on pancreaticoduodenectomy: a randomized controlled trial. J Hepatobiliary Pancreat Sci 2019;26:360-369.

10. Buhrman WC, Lyman WB, Kirks RC, Passeri M, Vrochides D. Current state of Enhanced Recovery After Surgery in hepatopancreatobiliary surgery. J Laparoendosc Adv Surg Tech A 2018;28:1471-1475.

11. Lassen K, Coolsen MM, Slim K, Carli F, de Aguilar-Nascimento JE, Schäfer M, et al. Guidelines for perioperative care for pancreaticoduodenectomy: Enhanced Recovery After Surgery $\left(\right.$ ERAS $^{\circledR}$ ) Society recommendations. World J Surg 2013;37:240-258.

12. Gouma DJ, van Geenen RC, van Gulik TM, de Haan RJ, de Wit LT, Busch OR, et al. Rates of complications and death after pancreaticoduodenectomy: risk factors and the impact of hospital volume. Ann Surg 2000;232:786-795.

13. Sohn TA, Yeo CJ, Cameron JL, Koniaris L, Kaushal S, Abrams RA, et al. Resected adenocarcinoma of the pancreas-616 patients: results, outcomes, and prognostic indicators. J Gastrointest Surg 2000;4:567-579.

14. Shin SH, Kim SC, Song KB, Hwang DW, Lee JH, Park KM, et al. Chronologic changes in clinical and survival features of pancreatic ductal adenocarcinoma since 2000: a single-center experience with 2,029 patients. Surgery 2018;164:432-442.

15. Jarnagin WR, Gonen M, Fong Y, DeMatteo RP, Ben-Porat L, Little $\mathrm{S}$, et al. Improvement in perioperative outcome after hepatic resection: analysis of 1,803 consecutive cases over the past decade. Ann Surg 2002;236:397-406; discussion 406-407.

16. Aloia TA, Fahy BN, Fischer CP, Jones SL, Duchini A, Galati $\mathrm{J}$, et al. Predicting poor outcome following hepatectomy: analysis of 2313 hepatectomies in the NSQIP database. HPB (Oxford) 2009; 11:510-515.

17. Zimmitti G, Roses RE, Andreou A, Shindoh J, Curley SA, Aloia TA, et al. Greater complexity of liver surgery is not associated with an increased incidence of liver-related complications except for bile leak: an experience with 2,628 consecutive resections. J Gastrointest Surg 2013;17:57-64; discussion 64-65.

18. Jones C, Kelliher L, Dickinson M, Riga A, Worthington T, Scott $\mathrm{MJ}$, et al. Randomized clinical trial on enhanced recovery versus standard care following open liver resection. Br J Surg 2013;100: 1015-1024. 
19. Schultz NA, Larsen PN, Klarskov B, Plum LM, Frederiksen HJ, Christensen BM, et al. Evaluation of a fast-track programme for patients undergoing liver resection. Br J Surg 2013;100:138-143.

20. Braga M, Pecorelli N, Ariotti R, Capretti G, Greco M, Balzano $\mathrm{G}$, et al. Enhanced recovery after surgery pathway in patients undergoing pancreaticoduodenectomy. World J Surg 2014;38: 2960-2966.

21. Coolsen MM, van Dam RM, Chigharoe A, Olde Damink SW, Dejong $\mathrm{CH}$. Improving outcome after pancreaticoduodenectomy: experiences with implementing an enhanced recovery after surgery (ERAS) program. Dig Surg 2014;31:177-184.

22. Williamsson C, Karlsson N, Sturesson C, Lindell G, Andersson $\mathrm{R}$, Tingstedt $\mathrm{B}$. Impact of a fast-track surgery programme for pancreaticoduodenectomy. Br J Surg 2015;102:1133-1141.
23. Lavu H, Kennedy EP, Mazo R, Stewart RJ, Greenleaf C, Grenda $\mathrm{DR}$, et al. Preoperative mechanical bowel preparation does not offer a benefit for patients who undergo pancreaticoduodenectomy. Surgery 2010;148:278-284.

24. Callery MP, Pratt WB, Kent TS, Chaikof EL, Vollmer CM Jr. A prospectively validated clinical risk score accurately predicts pancreatic fistula after pancreatoduodenectomy. J Am Coll Surg 2013;216:1-14.

25. McMillan MT, Malleo G, Bassi C, Butturini G, Salvia R, Roses $\mathrm{RE}$, et al. Drain management after pancreatoduodenectomy: reappraisal of a prospective randomized trial using risk stratification. J Am Coll Surg 2015;221:798-809.

26. Ljungqvist O, Søreide E. Preoperative fasting. Br J Surg 2003; 90:400-406. 